\title{
The Role of Active Oxide Species for Electrochemical Water Oxidation on the Surface of 3d-Metal Phosphides
}

\author{
Kaili Liu, Fengmei Wang, Peng He, Tofik Ahmed Shifa, Zhenxing Wang, \\ Zhongzhou Cheng, Xueying Zhan, and Jun He*
}

Transition metal phosphides (TMPs) have recently been utilized as promising electrocatalysts for oxygen evolution reaction (OER) in alkaline media. The metal oxides or hydroxides formed on their surface during the OER process are hypothesized to play an important role. However, their exact role is yet to be elucidated. Here unambiguous justification regarding the active role of oxo(hydroxo) species on $\mathrm{O}-\mathrm{Ni}_{(1-x)} \mathrm{Fe}_{x} \mathrm{P}_{2}$ nanosheet with pyrite structure is shown. These $\mathrm{O}-\mathrm{Ni}_{(1-x)} \mathrm{Fe}_{x} \mathrm{P}_{2}(x=0.25)$ nanosheets demonstrate greatly improved OER performance than their corresponding hydroxide and oxide counterparts do. From density function theory (DFT) calculations, it is found that the introduction of iron into the pyrite-phased $\mathrm{NiP}_{2}$ alters OER steps occurred on the surface. Notably, the partially oxidized surface of O-Ni $\mathrm{N}_{(1-x)} \mathrm{Fe}_{x} \mathrm{P}_{2}$ nanosheets is vital to improve the local environment and accelerate the reaction steps. This study sheds light on the OER mechanism of the 3d TMP electrocatalyst and opens up a way to develop efficient and low-cost electrocatalysts.

non-noble metal-based OER electrocatalysts. In this regard, there is an important branch of electrocatalytic water splitting study dealing with the development of $3 \mathrm{~d}$ transition metal (TMs), such as Fe, Co, Ni, and $\mathrm{Cu}$, based catalysts. Transition metal phosphides (TMPs), including $\mathrm{FeP}^{[3]}$ $\mathrm{Ni}_{2} \mathrm{P},{ }^{[4,5]} \mathrm{Ni}_{12} \mathrm{P}_{5},{ }^{[6]} \mathrm{Co}_{2} \mathrm{P},{ }^{[7]} \mathrm{CoP}_{2},{ }^{[8]} \mathrm{CoP},{ }^{[9]}$ and $\mathrm{Mo}_{3} \mathrm{P},{ }^{[10]}$ have been synthesized as efficient electrocatalysts for OER in alkaline media.

Nickel phosphides $\left(\mathrm{NiP}_{\mathrm{x}}\right)$, especially, have attracted extensive interest nowadays mainly due to their superior catalytic capacity for OER. According to the ratio of Ni:P, it usually consists of metal-rich phases with $x<1$ (e.g., $\mathrm{Ni}_{2} \mathrm{P}, \mathrm{Ni}_{12} \mathrm{P}_{5}$, and $\mathrm{Ni}_{5} \mathrm{P}_{4}$ ) and phosphorus-rich phases with $x>1$ (e.g., $\mathrm{NiP}_{2}$ and $\mathrm{NiP}_{3}$ ). ${ }^{[11]}$ The metalrich phases deem as electrocatalysts in OER process are profoundly studied. ${ }^{[4,12,13]}$

Oxygen evolution reaction (OER, $2 \mathrm{H}_{2} \mathrm{O} \rightarrow 4 e^{-}+4 \mathrm{H}^{+}+\mathrm{O}_{2}$ ) is an unavoidably essential step in the water splitting and carbon dioxide $\left(\mathrm{CO}_{2}\right)$ reduction, which are key process for tackling energy crisis and climate change. ${ }^{[1]}$ Unfortunately, this reaction is kinetically sluggish with the transfer of four electrons and formation of covalent $\mathrm{O}-\mathrm{O}$ band. ${ }^{[2]}$ This situation makes the design of appropriate electrocatalysts to derive OER exceptionally challenging. The noble metal-based catalysts like $\mathrm{IrO}_{2}$ and $\mathrm{RuO}_{2}$ exhibit excellent OER activity, but their scarcity and high-cost hinder the large-scale application. Thus, tremendous efforts and progress have been made in recent years to develop

K. Liu, Dr. F. M. Wang, P. He, T. A. Shifa, Prof. Z. Wang,

Z. Cheng, X. Zhan, Prof. J. He

CAS Center for Excellence in Nanoscience

CAS Key Laboratory of Nanosystem and Hierarchical Fabrication

National Center for Nanoscience and Technology

No.11 ZhongGuanCun BeiYiTiao, Beijing 100190, P. R. China

E-mail: hej@nanoctr.cn

K. Liu, T. A. Shifa, Prof. J. He

University of Chinese Academy of Sciences

No. 19A Yuquan Road, Beijing 100049, China

K. Liu

Sino-Danish Center for Education and Research

Beijing 100190, P. R. China

The ORCID identification number(s) for the author(s) of this article can be found under https://doi.org/10.1002/aenm.201703290.

DOI: 10.1002/aenm.201703290
Yet, the study with regard to phosphorous-rich phases is still at its infant stage. Notably, phosphorus-enriched $\mathrm{NiP}_{2}$ crystallized in cubic $\mathrm{Pa}-3$ pyrite-type structure is found to be more electronically conductive, even comparable with pyrolytic carbon. ${ }^{[14]}$ Moreover, compared with the sole nickel phosphide, some reported works show that the incorporation of heterometal, like iron (Fe), atoms into the nickel phosphide increases the catalytic activity. ${ }^{[15,16]}$ Theoretical calculations and experimental results demonstrated that iron serves multiple purposes: (1) it modifies the electronic structure and greatly increases the metallic character of nickel phosphide via introducing the Fe $3 \mathrm{~d}$ state at the Fermi level;[17] (2) it improves the redox activity of the catalyst surface as a result of lowering activation energy of oxygen adsorption. ${ }^{[18,19]}$ Besides the aforementioned two points, we demonstrate herein that introducing iron also induces the change of active sites and enables thermodynamically more efficient oxygen adsorption process on the catalyst surface employing the density functional theoretical (DFT) calculations. As shown in Figure 1a, the adsorption energy of $\mathrm{O}$ atom on $\mathrm{Ni}_{(1-x)} \mathrm{Fe}_{x} \mathrm{P}_{2}(111)(E(\mathrm{O})=-6.62 \mathrm{eV})$ is much more negative than that on $\mathrm{NiP}_{2}(111)(E(\mathrm{O})=-4.42 \mathrm{eV})$. This result suggests a much easier oxygen atom adsorption on $\mathrm{Ni}_{(1-x)} \mathrm{Fe}_{x} \mathrm{P}_{2}$ surface. Interestingly, the adsorption site of $\mathrm{O}$ atom likewise is changed to $\mathrm{Fe}-\mathrm{Fe}$ bridge site on the ternary $\mathrm{Ni}_{(1-x)} \mathrm{Fe}_{x} \mathrm{P}_{2}$, while that is the $\mathrm{Ni}-\mathrm{Ni}$ bridge site on the binary $\mathrm{NiP}_{2}$. Meanwhile, the intermediate will automatically shift from Ni sites to Fe sites under the relaxation process (Figure S1a,b, Supporting Information). 
(a)

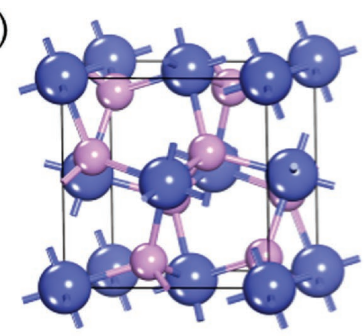

$\mathrm{NiP}_{2}$

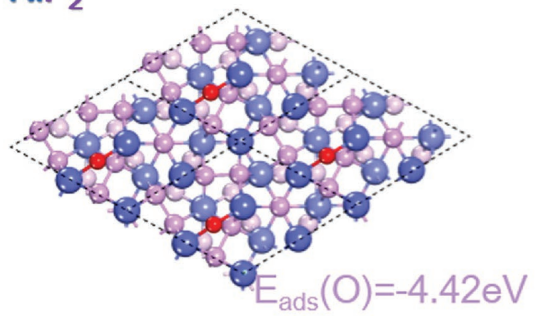

\section{(n)}

(n)
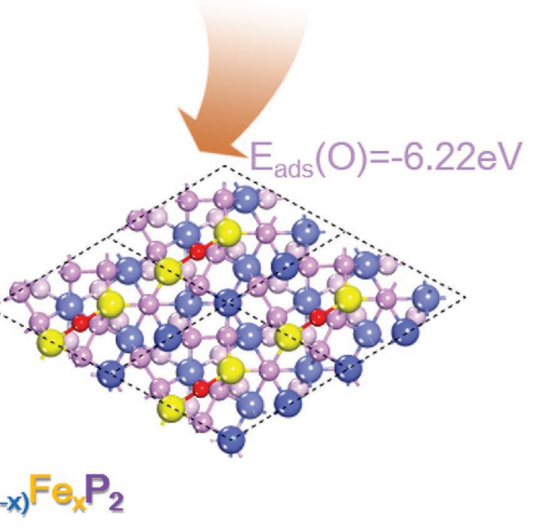

(b)

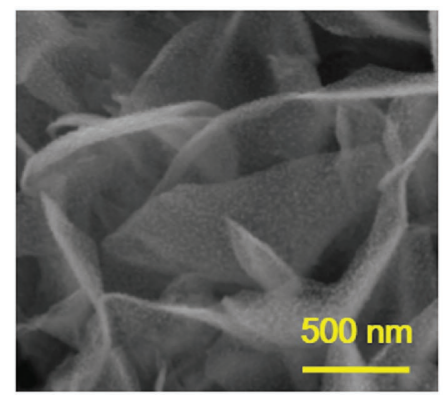

(c)

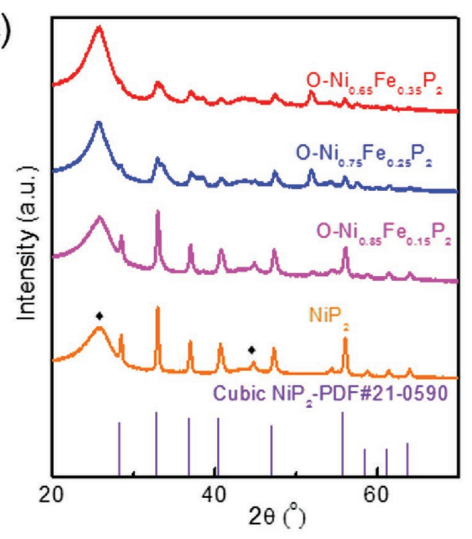

Figure 1. The atomic configurations of pyrite-type $\mathrm{NiP}_{2}$ bulk (a, top, left) with oxygen atoms adsorbed on $\mathrm{NiP}_{2}(111)$ surface $(\mathrm{a}$, top, right, topview) and $\mathrm{Ni}_{(1-x)} \mathrm{Fe}_{x} \mathrm{P}_{2}$ bulk (a, bottom, left) with oxygen atoms adsorbed on $\mathrm{Ni}_{(1-x)} \mathrm{Fe}_{x} \mathrm{P}_{2}(111)$ surface (a, bottom, right, topview). The blue, yellow, pink, and red balls are $\mathrm{Ni}, \mathrm{Fe}, \mathrm{P}$, and $\mathrm{O}$ atoms, respectively. The sublayer balls are light shade. A more negative adsorption energy of an oxygen atom on the Fe site of $\mathrm{Ni}_{(1-x)} \mathrm{Fe}_{X} \mathrm{P}_{2}(111)$ surface suggests the active site of OER is changed. b) SEM image of the O- $\mathrm{Ni}_{0.75} \mathrm{Fe}_{0.25} \mathrm{P}_{2}$ nanosheets on CFs. c) XRD patterns of various samples with different $\mathrm{Ni} / \mathrm{Fe}$ ratios.

According to recent findings, the oxo/hydroxo species formed on the surface of nickel phosphides during the OER process are identified to be active for the intended catalysis. ${ }^{[13,15,17,20,21]}$ However, the exact nature and role of these oxygen species, which is helpful to understand the OER process at the atomic scale, on the catalyst surface remains elusive.

Considering these challenges, we synthesized ternary porous $\mathrm{Ni}_{(1-x)} \mathrm{Fe}_{x} \mathrm{P}_{2}(0<x<1)$ nanosheets via chemical vapor deposition method. Impressively, this experiment brought a different and quite interesting oxide species on the surface of porous $\mathrm{Ni}_{(1-x)} \mathrm{Fe}_{x} \mathrm{P}_{2}(0<x<1)$. These uniform and partially oxidized $\mathrm{Ni}_{(1-x)} \mathrm{Fe}_{x} \mathrm{P}_{2}(0<x<1)$ nanosheets (denoted as $\left.\mathrm{O}-\mathrm{Ni}_{(1-x)} \mathrm{Fe}_{x} \mathrm{P}_{2}\right)$ demonstrate much better OER performance than the corresponding hydroxide and oxide counterparts do in the alkaline $(1.0 \mathrm{~m} \mathrm{KOH})$ electrolyte. Additionally, the electrocatalytic activity of the ternary nanosheets can be tuned via controlling the content of iron. The porous $\mathrm{O}-\mathrm{Ni}_{0.75} \mathrm{Fe}_{0.25} \mathrm{P}_{2}$ nanosheets demonstrate the best performance with the overpotential of $155 \mathrm{mV}$ at $10 \mathrm{~mA} \mathrm{~cm}{ }^{-2}$. It outperforms the $\mathrm{Ni}_{0.75} \mathrm{Fe}_{0.25}(\mathrm{OH})_{\mathrm{y}}$ and $\mathrm{Ni}_{0.75} \mathrm{Fe}_{0.25} \mathrm{O}_{\mathrm{y}}$ nanosheets whose overpotentials are 280 and $430 \mathrm{mV}$, respectively, at the same current density. Based on the DFT computational calculations, we first find that the introduction of iron into the pyrite-phased $\mathrm{NiP}_{2}$ changes the reaction steps of OER process occurred on the surface. Notably, the partially oxidized surface of $\mathrm{O}-\mathrm{Ni}_{(1-x)} \mathrm{Fe}_{x} \mathrm{P}_{2}$ nanosheets is vital to improve the local environment and accelerate the reaction steps. This work uncovers the function of oxygen species on the surface of pyrite-phased $\mathrm{TMP}_{x}$ and brings insight understanding of OER mechanism on the $3 \mathrm{~d}$ transition metal diphosphide electrocatalysts.

Porous $\mathrm{O}-\mathrm{Ni}_{(1-x)} \mathrm{Fe}_{x} \mathrm{P}_{2}(0 \leq x \leq 1)$ nanosheets on conductive carbon fibers (CFs) were sequentially synthesized by hydrothermal method and phosphorization reaction. First, Ni or $\mathrm{Ni}_{1-x} \mathrm{Fe}_{x}$-based hydroxide nanosheets (Figure S2a,b, Supporting Information) were directly grown on the $\mathrm{CFs}$ with various ratio of $\mathrm{Ni} / \mathrm{Fe}$ precursor $\left(\mathrm{Ni}\left(\mathrm{NO}_{3}\right)_{2} \cdot 6 \mathrm{H}_{2} \mathrm{O} / \mathrm{Fe}\left(\mathrm{NO}_{3}\right)_{3} \cdot 9 \mathrm{H}_{2} \mathrm{O}\right) \cdot{ }^{[22]}$ The X-ray diffraction (XRD) pattern (Figure S2e, Supporting Information) of the $\mathrm{Ni}_{1-x} \mathrm{Fe}_{x}$-based nanosheets shows the phase of $\mathrm{NiO}(\mathrm{OH})_{\mathrm{y}}$ (PDF\# 27-0340) and $\mathrm{FeO}(\mathrm{OH})$ (PDF \#75-1549). Subsequently, these $\mathrm{Ni}_{(1-x)} \mathrm{Fe}_{x}(\mathrm{OH})_{y}$ nanosheets were reacted with red phosphorous powder at $500{ }^{\circ} \mathrm{C}$ under Ar gas flowing to obtain the $\mathrm{O}-\mathrm{Ni}_{(1-x)} \mathrm{Fe}_{x} \mathrm{P}_{2}$ nanosheets. The morphologies of the $\mathrm{NiP}_{2}$ and $\mathrm{O}-\mathrm{Ni}_{(1-x)} \mathrm{Fe}_{x} \mathrm{P}_{2}$ were characterized by scanning electron microscopy (SEM) and transmission electron microscopy (TEM), the resulting images are shown in Figure 1b, Figure S2c,d and Figure S3 (Supporting Information). The surface of CFs is uniformly covered by the synthesized nanosheets. From the high-magnification SEM (Figure 1b) and TEM images (Figure S2a, Supporting Information), the $\mathrm{O}-\mathrm{Ni}_{(1-x)} \mathrm{Fe}_{x} \mathrm{P}_{2}$ nanosheets present a rough and porous feature. Figure 1c shows the XRD patterns of a series of samples. These diffractograms match well with the pyrite-type structure of cubic $\mathrm{NiP}_{2}$ (PDF\# 21-0590). Compared with the $\mathrm{NiP}_{2}$ nanosheets, there is no obvious difference in the structure of $\mathrm{O}-\mathrm{Ni}_{(1-x)} \mathrm{Fe}_{x} \mathrm{P}_{2}$ nanosheets except for a slight deviation. A clear lattice fringes with interplanar spacing of $0.28 \mathrm{~nm}$ in 

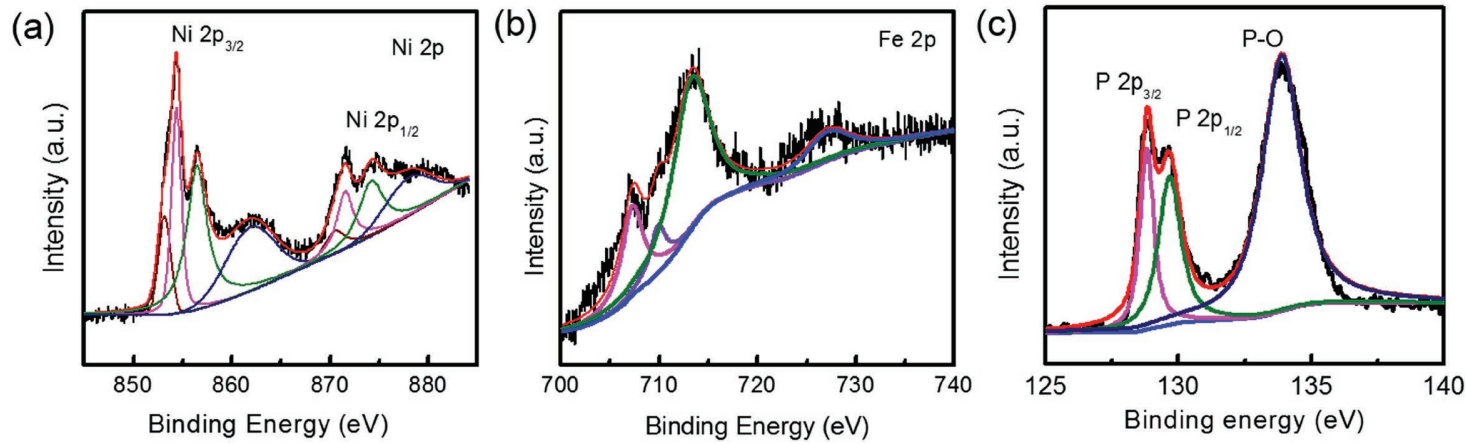

Figure 2. Component analysis of $\mathrm{O}-\mathrm{Ni}_{0.75} \mathrm{Fe}_{0.25} \mathrm{P}_{2}$ nanosheets. High-resolution XPS spectra of a) $\left.\mathrm{Ni} 2 \mathrm{p}, \mathrm{b}\right) \mathrm{Fe} 2 \mathrm{p}$, and c) $\mathrm{P} 2 \mathrm{p}$ regions.

the high-resolution TEM (HRTEM, Figure S1b, Supporting Information) of $\mathrm{O}-\mathrm{Ni}_{0.75} \mathrm{Fe}_{0.25} \mathrm{P}_{2}$ nanosheet is indexed to (200) crystal plane. To further discover the elemental distribution in the $\mathrm{O}-\mathrm{Ni}_{0.75} \mathrm{Fe}_{0.25} \mathrm{P}_{2}$ nanosheet, the energy-dispersive X-ray (EDX) spectrum (Figure S3, Supporting Information) and the elemental mapping images (Figure S2c, Supporting Information) were investigated. They show the uniform distribution of $\mathrm{Ni}, \mathrm{Fe}$, and $\mathrm{P}$ elements in the entire nanosheet. More importantly, the $\mathrm{O}$ element is also detected in the nanosheet (Figure S4a, Supporting Information). The atomic ratio of Ni/ $\mathrm{Fe}$ for $\mathrm{O}-\mathrm{Ni}_{(1-x)} \mathrm{Fe}_{x} \mathrm{P}_{2}(x=0,0.15,0.25,0.35)$ nanosheets were also confirmed by EDX.

As a surface-sensitive quantitative spectroscopic technique, X-ray photoelectron spectroscopy (XPS) was performed to further reveal the chemical states of $\mathrm{Ni}, \mathrm{Fe}$, and $\mathrm{P}$ in the $\mathrm{O}-\mathrm{Ni}_{0.75} \mathrm{Fe}_{0.25} \mathrm{P}_{2}$ nanosheet. The survey XPS spectrum (Figure S4b, Supporting Information) of $\mathrm{O}-\mathrm{Ni}_{0.75} \mathrm{Fe}_{0.25} \mathrm{P}_{2}$ nanosheets confirms the presence of $\mathrm{Ni}, \mathrm{Fe}, \mathrm{P}$, and $\mathrm{O}$ elements. The high-resolution Ni 2p spectrum in Figure $2 \mathrm{a}$ can be fitted into four pairs of peaks. The peaks at $853.2 \mathrm{eV}$ and $870.5 \mathrm{eV}$ are assigned to the binding energies of $\mathrm{Ni} 2 \mathrm{p}_{3 / 2}$ and $\mathrm{Ni} 2 \mathrm{p}_{1 / 2}$ for Ni-P group, while the peaks located at 854.3 and $856.6 \mathrm{eV}$ are in consistent with the binding energy of $\mathrm{Ni} 2 \mathrm{p}_{3 / 2}$ for $\mathrm{Ni}$ oxides and hydroxide species. ${ }^{[23]}$ The left peaks of 861.0 and $878.2 \mathrm{eV}$ are owing to Ni satellite peaks. In the spectrum of $\mathrm{Fe}$ $2 \mathrm{p}$ (Figure $2 \mathrm{~b}$ ), the peak located at $707.3 \mathrm{eV}$ can be regarded as iron bonded to phosphorus and the others at 709.9, 713.6, and $726.9 \mathrm{eV}$ are attributed to Fe oxide species. These results suggest that the surface of the synthesized $\mathrm{O}-\mathrm{Ni}_{0.75} \mathrm{Fe}_{0.25} \mathrm{P}_{2}$ nanosheets is partially oxidized. Of particular note is that there is no obvious oxide phase from the XRD patterns and HRTEM image, confirming that the major phase of the sample is pyritephased $\mathrm{Ni}_{0.75} \mathrm{Fe}_{0.25} \mathrm{P}_{2}$. Figure 2c shows the characteristic XPS peaks of $\mathrm{P} 2 \mathrm{p}_{3 / 2}$ and $\mathrm{P} 2 \mathrm{p}_{1 / 2}$ which are located at 127.3 and $129.2 \mathrm{eV}$ further corroborating the successful formation of ternary $\mathrm{Ni}_{0.75} \mathrm{Fe}_{0.25} \mathrm{P}_{2}$. Similarly, the strong peak at $133.6 \mathrm{eV}$ also confirm the oxidized metal phosphate species, same with the case in $\mathrm{Ni}$ and Fe. ${ }^{[24]}$

The electrocatalytic activities of various $\mathrm{O}-\mathrm{Ni}_{(1-x)} \mathrm{Fe}_{x} \mathrm{P}_{2}$ $(0<x<1)$ nanosheets are evaluated as electrocatalysts for OER in $1.0 \mathrm{M} \mathrm{KOH}$ solution $\left(\mathrm{O}_{2}\right.$ saturated) using the typical threeelectrode system. A piece of $\mathrm{CFs}$ onto which the $\mathrm{O}-\mathrm{Ni}_{(1-x)} \mathrm{Fe}_{x} \mathrm{P}_{2}$ nanosheets were grown can be directly utilized as working electrode (WE), while a mercuric oxide electrode (MOE) $(\mathrm{Hg} / \mathrm{HgO} /$ $\mathrm{OH}^{-}$) and a graphite rod were used as reference electrode (RE) and counter electrode (CE), respectively. As a comparison, the $\mathrm{NiP}_{2}, \quad \mathrm{Ni}_{0.75} \mathrm{Fe}_{0.25}(\mathrm{OH})_{\mathrm{y}}$ and $\mathrm{Ni}_{0.75} \mathrm{Fe}_{0.25} \mathrm{O}_{\gamma}$ nanosheets (Supporting Information) were also measured under the same condition. The polarization curves after iR-correction ${ }^{[25]}$ (Figure 3a) of different electrocatalysts were collected from liner sweep voltammograms (LSV) with a scan rate of $2 \mathrm{mV} \mathrm{s}^{-1}$. It can be clearly seen that the $\mathrm{O}-\mathrm{Ni}_{0.75} \mathrm{Fe}_{0.25} \mathrm{P}_{2}$ nanosheets only needs $155 \mathrm{mV}$ to achieve a current density of $10 \mathrm{~mA} \mathrm{~cm}^{-2}$. This value is not only lower than the one required in the case of $\mathrm{NiP}_{2}$ nanosheets $(180 \mathrm{mV})$ but also outperforms the corresponding hydroxide and oxide counterparts, namely $\mathrm{Ni}_{0.75} \mathrm{Fe}_{0.25}(\mathrm{OH})_{y}$ and $\mathrm{Ni}_{0.75} \mathrm{Fe}_{0.25} \mathrm{O}_{\mathrm{y}}$ nanosheets with the overpotential of 280 and $430 \mathrm{mV}$ at $10 \mathrm{~mA} \mathrm{~cm}^{-2}$, respectively. The corresponding Tafel plots of various electrodes are shown in Figure $3 \mathrm{~b}$. The Tafel slopes of $\mathrm{O}-\mathrm{Ni}_{0.75} \mathrm{Fe}_{0.25} \mathrm{P}_{2}$ and $\mathrm{NiP}_{2}$ nanosheets are 55 and $53 \mathrm{mV} \mathrm{dec}^{-1}$, which are much lower than that of $\mathrm{Ni}_{0.75} \mathrm{Fe}_{0.25}(\mathrm{OH})_{y}$

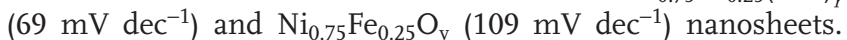
This finding demonstrates that much faster OER rate occurred on the surface of $\mathrm{O}-\mathrm{Ni}_{0.75} \mathrm{Fe}_{0.25} \mathrm{P}_{2}$ nanosheets. From the above results, the partially oxidized surface plays a vital role on the observed excellent OER activity of O- $\mathrm{Ni}_{0.75} \mathrm{Fe}_{0.25} \mathrm{P}_{2}$ nanosheets. The Ni-Fe oxo/hydroxo species on the surface of $\mathrm{Ni}_{(1-x)} \mathrm{Fe}_{x} \mathrm{P}_{2}$, as detected from the previous XPS analysis, are acknowledged for improving the OER activity of $\mathrm{O}-\mathrm{Ni}_{(1-x)} \mathrm{Fe}_{\mathrm{x}} \mathrm{P}_{2}$ nanosheets via tuning the electrochemical environment, also confirmed in some recent reported works. ${ }^{[15,26]}$ As the reaction continues, much more Ni-Fe oxo/hydroxo species were produced. From the corresponding SEM and TEM images (Figure S5a-c, Supporting Information) of the $\mathrm{O}-\mathrm{Ni}_{0.75} \mathrm{Fe}_{0.25} \mathrm{P}_{2}$ nanosheets after OER test, there is negligible change on the morphology of the nanosheets. However, the depletion of $\mathrm{P}$ atoms and production of oxo/hydroxo species on the surface are further confirmed by the XRD pattern (Figure S5d, Supporting Information), EDX (Figure S6a, Supporting Information), and XPS analysis (Figure S6b-d, Supporting Information). The amorphous oxides phase from the XRD pattern finally obtained after the measurement in the alkaline media. The Ni $2 p_{3 / 2}$ peak shows a shift in binding energy from 853.2 to $855.1 \mathrm{eV}$ in $\mathrm{O}-\mathrm{Ni}_{0.75} \mathrm{Fe}_{0.25} \mathrm{P}_{2}$ nanosheets before and after OER test, corroborating the formation of Ni oxide. This phenomenon is common for transition metal chalcogenides ${ }^{[26,27]}$ and phosphides ${ }^{[15]}$ used as electrocatalysts for OER. Additionally, the influence of $\mathrm{Ni} / \mathrm{Fe}$ ratio $(x=0.15,0.25,0.35)$ in the $\mathrm{O}-\mathrm{Ni}_{(1-x)} \mathrm{Fe}_{x} \mathrm{P}_{2}$ nanosheets on the OER electrocatalytic activity was also probed (Figure S7, Supporting Information). Their overpotentials at $10 \mathrm{~mA} \mathrm{~cm}^{-2}$ and 
(a)

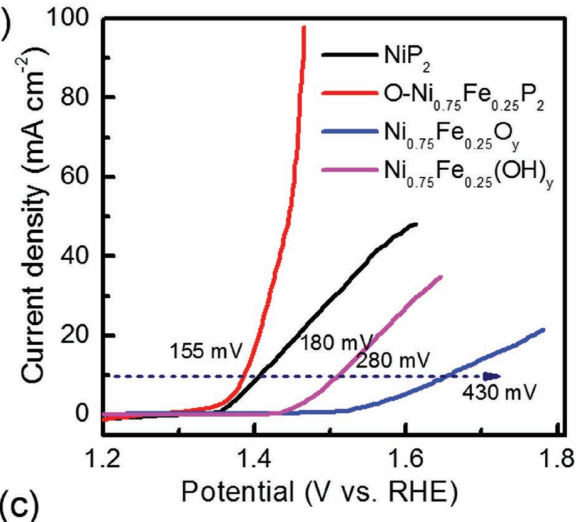

(c)

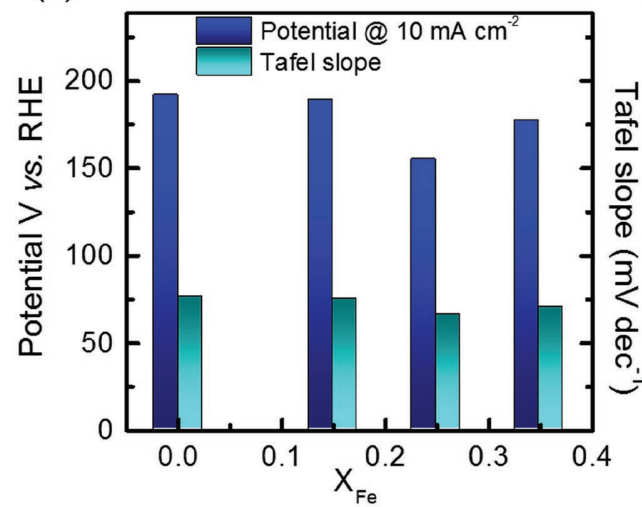

(b)

(d)
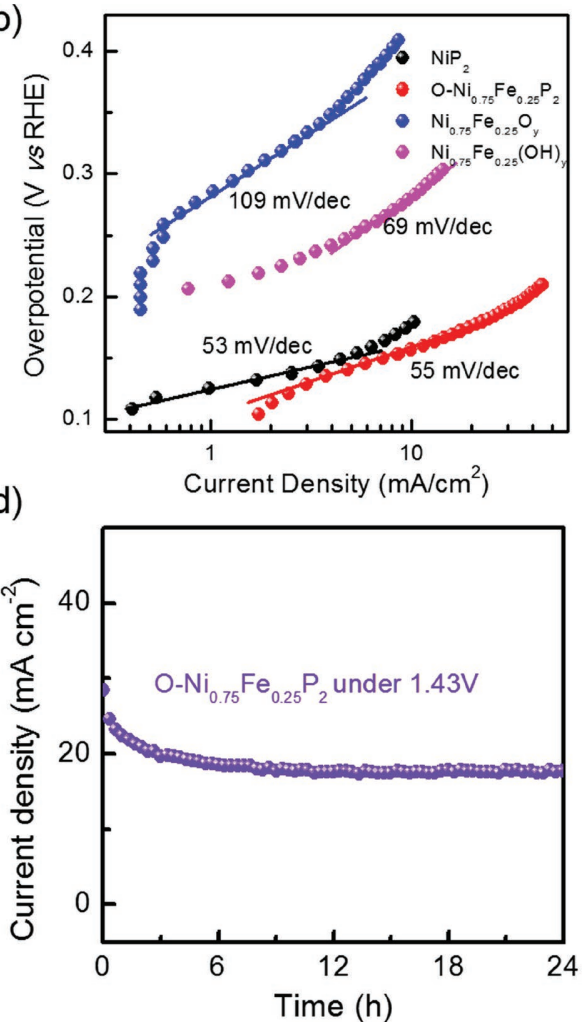

Figure 3. a) Polarization curves and corresponding b) Tafel plots for $\mathrm{NiP}_{2}, \mathrm{O}-\mathrm{Ni}_{0.75} \mathrm{Fe}_{0.25} \mathrm{P}_{2}, \mathrm{Ni}_{0.75} \mathrm{Fe}_{0.25}(\mathrm{OH})_{\gamma}$ and $\mathrm{Ni}_{0.75} \mathrm{Fe}_{0.25} \mathrm{O}_{\gamma}$ nanosheets in $1.0 \mathrm{~m} \mathrm{KOH}$ solution. c) Overpotentials required at $10 \mathrm{~mA} \mathrm{~cm}{ }^{-2}$ and the Tafel slopes for different $\mathrm{O}-\mathrm{Ni}_{(1-x)} \mathrm{Fe}_{x} \mathrm{P}_{2}$ nanosheets with $x=0,0.15,0.25,0.35$. d) Chronoamperometric curve of $\mathrm{O}-\mathrm{Ni}_{0.75} \mathrm{Fe}_{0.25} \mathrm{P}_{2}$ nanosheets at the potential of $1.43 \mathrm{~V}$ within $24 \mathrm{~h}$.

corresponding Tafel slopes are illustrated in Figure 3c, showing the best activity of $\mathrm{O}-\mathrm{Ni}_{0.75} \mathrm{Fe}_{0.25} \mathrm{P}_{2}$ nanosheets among them. Ultimately, its stability was determined via chronoamperometric measurement within $24 \mathrm{~h}$ at the potential of $1.43 \mathrm{~V}$ (vs RHE). The decrease in the OER performance after $2.5 \mathrm{~h}$ continuous measurement is observed. This result indicates the lower activity of the transition metal oxides/hydroxides, same with the results in the previous LSV curves.

Additionally, the catalytic performance toward hydrogen evolution reaction (HER) performance for the $\mathrm{O}-\mathrm{Ni}_{0.75} \mathrm{Fe}_{0.25} \mathrm{P}_{2}$ nanosheets was also evaluated in the $1.0 \mathrm{M} \mathrm{KOH}$ solution $\left(\mathrm{N}_{2}\right.$ saturated) with the same three-electrode system. Figure S8a (Supporting Information) displays the polarization curves of $\mathrm{O}-\mathrm{Ni}_{0.75} \mathrm{Fe}_{0.25} \mathrm{P}_{2}$ nanosheets, $\mathrm{NiP}_{2}$ nanosheets, and bare $\mathrm{CF}$ at a scan rate of $2 \mathrm{mV} \mathrm{s}^{-1}$. In connection to this, the $\mathrm{NiP}_{2}$ nanosheets need overpotential of $234 \mathrm{mV}$ vs RHE to reach at the current density of $10 \mathrm{~mA} \mathrm{~cm}{ }^{-2}$. But, the $\mathrm{O}-\mathrm{Ni}_{0.75} \mathrm{Fe}_{0.25} \mathrm{P}_{2}$ nanosheets only require overpotential of $169 \mathrm{mV}$ vs RHE to achieve the same current density. The overpotential at $10 \mathrm{~mA} \mathrm{~cm} \mathrm{~cm}^{-2}$ and corresponding Tafel slopes of the various $\mathrm{O}-\mathrm{Ni}_{(1-x)} \mathrm{Fe}_{x} \mathrm{P}_{2}(x=0.15,0.25,0.35)$ nanosheets are illustrated in Figure S8b (Supporting Information), showing the best HER activity of the $\mathrm{O}-\mathrm{Ni}_{0.75} \mathrm{Fe}_{0.25} \mathrm{P}_{2}$ nanosheets due to the optimized electronic structure after introducing Fe atoms. Different from the situation in OER process, the $\mathrm{O}-\mathrm{Ni}_{0.75} \mathrm{Fe}_{0.25} \mathrm{P}_{2}$ nanosheets reveal a negligible change in both morphology and phase (Figure S9, Supporting Information). Encouraged by the HER and OER performances of $\mathrm{O}-\mathrm{Ni}_{0.75} \mathrm{Fe}_{0.25} \mathrm{P}_{2}$ nanosheets, we further performed the overall water splitting using a two-electrode configuration in alkaline solution $(1.0 \mathrm{M} \mathrm{KOH})$. In this two-electrode system, the $\mathrm{O}-\mathrm{Ni}_{0.75} \mathrm{Fe}_{0.25} \mathrm{P}_{2}$ nanosheets electrodes served as both cathode and anode $\mathrm{O}-\mathrm{Ni}_{0.75} \mathrm{Fe}_{0.25} \mathrm{P}_{2} \| \mathrm{O}-\mathrm{Ni}_{0.75} \mathrm{Fe}_{0.25} \mathrm{P}_{2}$. Linear sweep voltammetric (LSV) measurements were carried out to estimate the performance of $\mathrm{O}-\mathrm{Ni}_{0.75} \mathrm{Fe}_{0.25} \mathrm{P}_{2} \|$ $\mathrm{O}-\mathrm{Ni}_{0.75} \mathrm{Fe}_{0.25} \mathrm{P}_{2}$ configuration for splitting the water into its component parts $\mathrm{H}_{2}$ and $\mathrm{O}_{2}$ (Figure $\mathrm{S} 10 \mathrm{a}$, Supporting Information). This configuration only needs a voltage of $1.58 \mathrm{~V}$ to reach a current density of $10 \mathrm{~mA} \mathrm{~cm}^{-2}$. Meanwhile, its stability in alkaline media was also tested and the result is shown in Figure S10b (Supporting Information), indicating only a slight change of potential is observed for overall water splitting.

In order to further understand the correlation between the surface component of nickel-iron phosphide and their OER activity, we conducted a series of DFT calculations. ${ }^{[28]}$ First, the free-energy change for OER on the $\mathrm{NiP}_{2}$ (111) surface (Figure 4a) was calculated. It clearly shows that all the reaction steps of OER on $\mathrm{NiP}_{2}(111)$ are endothermic at $U=0 \mathrm{~V}$. When the potential $(U)$ is increased to 1.23 or $1.60 \mathrm{~V}$, the third $\left(\mathrm{HO} * \rightarrow \mathrm{HOO}^{*}\right)$ and fourth $\left(\mathrm{HOO} * \rightarrow \mathrm{O}_{2}\right)$ steps become uphill in free energy. This result suggests the third and fourth steps are the rate-determining steps in the OER process on $\mathrm{NiP}_{2}(111)$. Based on the above experimental results, we, herein, displace $\mathrm{Ni}$ with two Fe atoms on $\mathrm{NiP}_{2}(111)$ to establish the $\mathrm{Ni}_{0.75} \mathrm{Fe}_{0.25} \mathrm{P}_{2}$ model. Similarly, the free-energy change on $\mathrm{Ni}_{0.75} \mathrm{Fe}_{0.25} \mathrm{P}_{2}$ (111) 
(a)

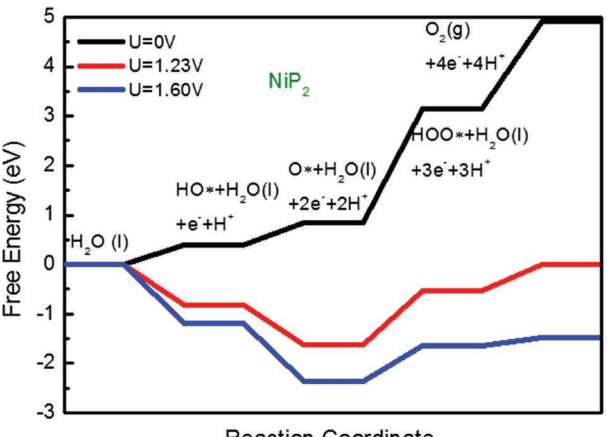

(b)

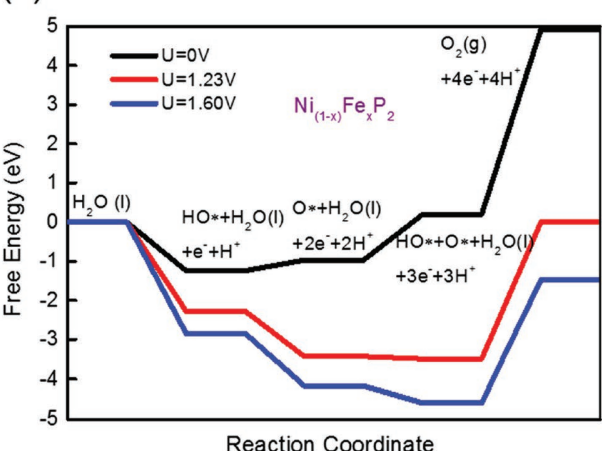

(c)
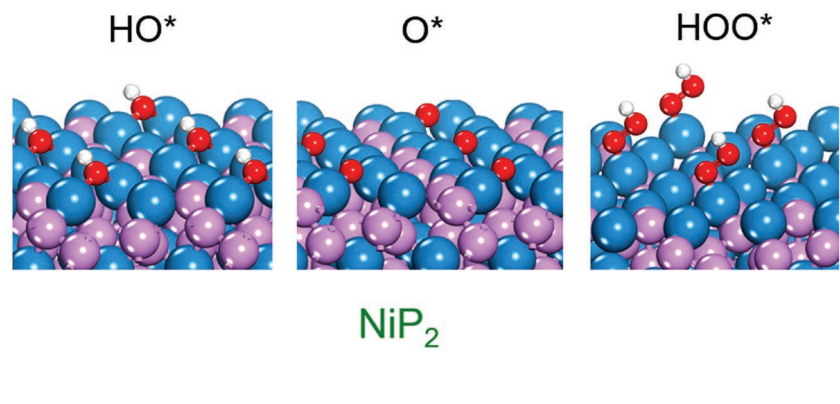

(d)

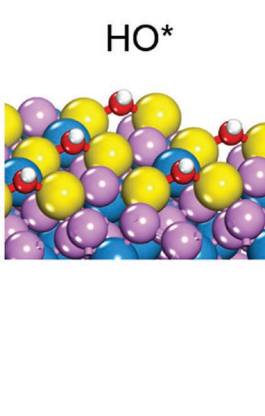

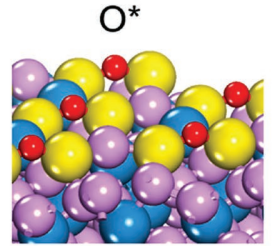

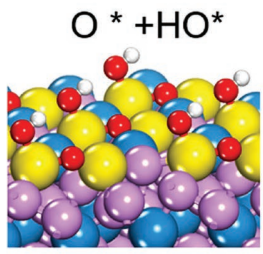

$\mathrm{Ni}_{0.75} \mathrm{Fe}_{0.25} \mathrm{P}_{2}$

Figure 4. Free energy diagram at different potentials for the oxygen evolution reaction on a) $\mathrm{NiP}_{2}(111)$ surface and b) $\mathrm{Ni}_{0.75} \mathrm{Fe}_{0.25} \mathrm{P}_{2}(111)$ surface. And atomic configurations of $\mathrm{OH}, \mathrm{O}$, and $\mathrm{OOH}$ adsorbing on c) $\mathrm{NiP}_{2}(111)$ surface and d) $\mathrm{Ni}_{0.75} \mathrm{Fe}_{0.25} \mathrm{P}_{2}(111)$ surface. The blue, yellow, pink, red, and white balls are $\mathrm{Ni}, \mathrm{Fe}, \mathrm{P}, \mathrm{O}$, and $\mathrm{H}$ atoms, respectively. Notably, the active site of OER changes from $\mathrm{Ni}$ site to Fe site for all intermediates.

was also calculated in Figure 4c. From the comparison of adsorption configuration in Figure $4 b$,d, we found a remarkable variation of active site between $\mathrm{NiP}_{2}$ (111) and $\mathrm{Ni}_{0.75} \mathrm{Fe}_{0.25} \mathrm{P}_{2}$ (111). Especially on $\mathrm{Ni}_{0.75} \mathrm{Fe}_{0.25} \mathrm{P}_{2}$ (111), all intermediates prefer adsorbing on the Fe sites rather than Ni sites. Significantly, from the corresponding free-energy diagram in Figure $4 \mathrm{c}$, the first step $\left(\mathrm{H}_{2} \mathrm{O} \rightarrow \mathrm{HO} *\right)$ of OER on $\mathrm{Ni}_{0.75} \mathrm{Fe}_{0.25} \mathrm{P}_{2}$ (111) is exothermic at $U=0$, suggesting the easier decomposition of the water molecule. While on the higher potentials $(U=1.23$ and $1.60 \mathrm{~V})$, the third step $(\mathrm{O} * \rightarrow \mathrm{HO} *)$ becomes "downhill." This means that the fourth step, namely the oxygen desorption process, is the only rate-limiting step for OER on $\mathrm{Ni}_{0.75} \mathrm{Fe}_{0.25} \mathrm{P}_{2}(111)$ in the practical test condition. Interestingly, the Fe sites have a strong capacity of decomposing $\mathrm{HOO}^{*}$ into $\mathrm{O} *$ and $\mathrm{HO}^{*}$. This is undesirable condition as it is not beneficial to obtain $\mathrm{O}_{2}$ molecule. Thus, the introduction of $\mathrm{Fe}$ is a "double-edged sword." On one hand, it can effectively reduce rate-limiting steps during the OER process. But on the other hand, it will reverse the step of $\mathrm{O} *+\mathrm{HO}^{*} \rightarrow \mathrm{HOO}^{*}$. Of particular note is that our $\mathrm{Ni}_{0.75} \mathrm{Fe}_{0.25} \mathrm{P}_{2}$ nanosheet is partially oxidized as corroborated from the above XPS analysis. The electrocatalyst used for OER is $\mathrm{O}-\mathrm{Ni}_{0.75} \mathrm{Fe}_{0.25} \mathrm{P}_{2}$ not pure $\mathrm{Ni}_{0.75} \mathrm{Fe}_{0.25} \mathrm{P}_{2}$ nanosheets. In this regards, the $\mathrm{O}-\mathrm{Ni}_{0.75} \mathrm{Fe}_{0.25} \mathrm{P}_{2}$ (111) surface is built through adsorbing $\mathrm{O}$ atoms on the $\mathrm{Fe}-\mathrm{Fe}$ bridge site, consistent with the configuration in Figure 1a. A 1/4 coverage of $\mathrm{O}$ atoms on $\mathrm{Ni}_{0.75} \mathrm{Fe}_{0.25} \mathrm{P}_{2}$ (111) was adopted. The adsorption energy profile of the various intermediates in OER process on the surface of $\mathrm{O}-\mathrm{Ni}_{0.75} \mathrm{Fe}_{0.25} \mathrm{P}_{2}$ (111) is depicted in Figure 5a. Interestingly, the fourth step is now recovered. It proceeds without the decomposition of the respective intermediate ( $\mathrm{HOO} *)$. Moreover, all the reaction steps of oxygen evolution are endothermic at $U=0 \mathrm{~V}$ on the surface of $\mathrm{O}-\mathrm{Ni}_{0.75} \mathrm{Fe}_{0.25} \mathrm{P}_{2}$ (111) (Figure 5b). However, at higher potentials $(1.23$ and $1.60 \mathrm{~V})$, the reaction steps, except for the third one $\left(\mathrm{O} * \rightarrow \mathrm{HOO}^{*}\right)$, are downhill. Notably, the intermediate $\mathrm{HOO}^{*}$ can easily be adsorbed on the Fe sites, which benefits the decomposition of $\mathrm{HOO} *$ into $\mathrm{O}_{2}$. To further clarify the difference in OER processes on the three surfaces, the free-energy diagram at the equilibrium potential $(U=1.23 \mathrm{~V})$ is summarized in Figure $5 \mathrm{c}$.

It is apparent that the partially oxidized surface on $\mathrm{Ni}_{0.75} \mathrm{Fe}_{0.25} \mathrm{P}_{2}$ (111) not only facilitates the change of active sites but also efficiently reduces the number of rate-determining steps. This unambiguously explains the reason why transition metal phosphides with oxo/hydroxo species on their surface after partial (not complete!) oxidation have demonstrated impressive OER catalytic activity in the experimental works. ${ }^{[15,17]}$ Thus, the theory and experiments are in an excellent agreement, suggesting the synergistic effect of the intrinsic TMPs and the oxo/hydroxo species on their surface successfully enhances the OER activity in the alkaline media. Our results demonstrate that there is a strong correlation between the local chemical environments on the surface of TMP-based electrocatalysts and the OER activity; that is the introduction of Fe and the oxo/hyoxo species on the TMPs can facilitate the OER rate through modulating the active sites and reaction processes. To our knowledge, this reaction dynamical function of oxo/hydoxo species on the surface has not been considered hitherto. 
(a)

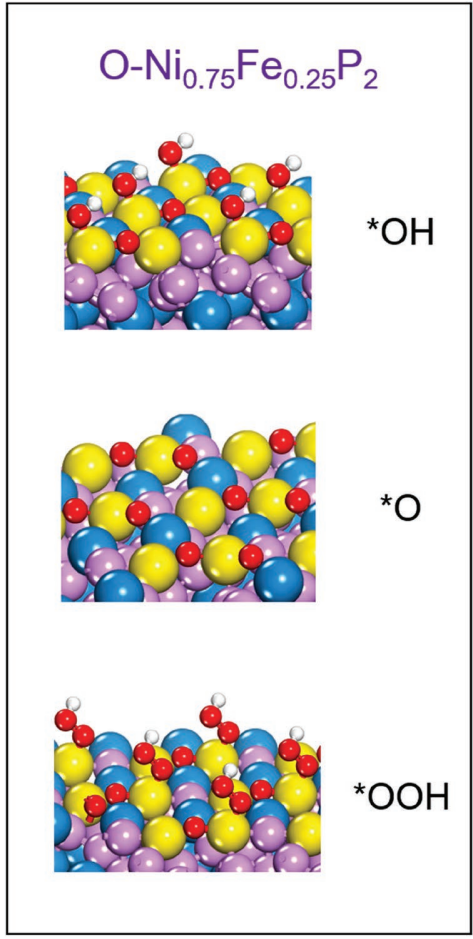

(b)

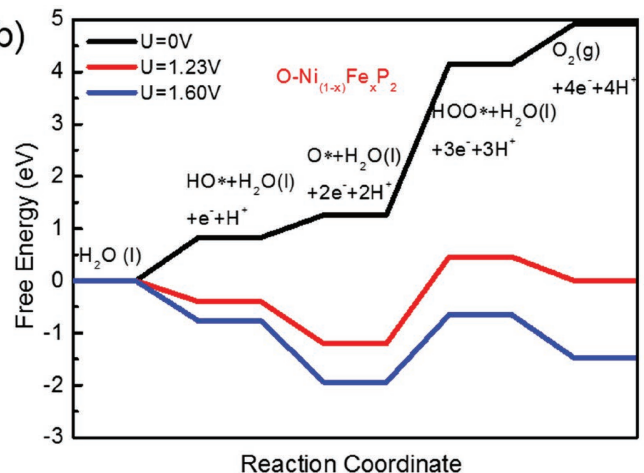

Reaction Coordinate

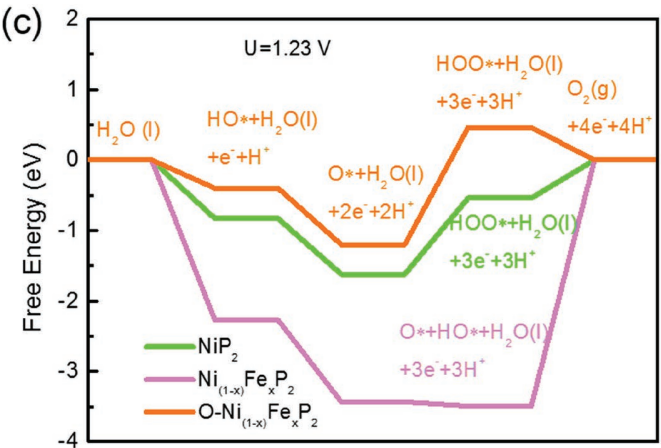

Reaction Coordinate

Figure 5. a) Atomic configurations of $\mathrm{OH}, \mathrm{O}$, and $\mathrm{OOH}$ adsorbing $\mathrm{O}-\mathrm{Ni}_{0.75} \mathrm{Fe}_{0.25} \mathrm{P}_{2}(111)$ surface. An oxygen atom adsorbs on the Fe-Fe bridge site first. Then all the intermediates can adsorb on the Fe top site steadily. b) Free-energy diagram at different potentials for the oxygen evolution reaction on $\mathrm{O}-\mathrm{Ni}_{0.75} \mathrm{Fe}_{0.25} \mathrm{P}_{2}(111)$ surface. $\left.c\right)$ Free-energy diagram at the equilibrium potential $(U=1.23 \mathrm{~V})$ on different surfaces. The blue, yellow, pink, red, and white balls are $\mathrm{Ni}, \mathrm{Fe}, \mathrm{P}, \mathrm{O}$, and $\mathrm{H}$ atoms, respectively.

In conclusion, porous $\mathrm{O}-\mathrm{Ni}_{(1-x)} \mathrm{Fe}_{x} \mathrm{P}_{2}$ nanosheet arrays were successfully fabricated on the CFs uniformly. Compared with the corresponding hydroxide and oxide nanosheets, the O- $\mathrm{Ni}_{0.75} \mathrm{Fe}_{0.25} \mathrm{P}_{2}$ nanosheets demonstrate remarkably increased OER performance in alkaline media. Significantly, the systematic DFT calculations were first adopted to uncover the reasons for its superior OER activity. With the introduction of $\mathrm{Fe}$ atoms into pyrite-phased $\mathrm{NiP}_{2}$, the active sites for adsorbing the oxygen species would change from Ni sites to Fe. Meanwhile, the $\mathrm{Fe}$ atoms could efficiently reduce rate-limiting steps in OER process. Unfortunately, it reverse the step of $\mathrm{O}^{*}+\mathrm{HO} * \rightarrow$ $\mathrm{HOO}^{*}$, which is not beneficial for $\mathrm{O}_{2}$ production. But, the partially oxidized surface, namely $\mathrm{O}-\mathrm{Ni}_{0.75} \mathrm{Fe}_{0.25} \mathrm{P}_{2}$, would optimize the local chemical environment to recover the reaction of $\mathrm{O}^{*+}$ $\mathrm{HO}^{*} \rightarrow \mathrm{HOO}^{*}$ along with the effective free energy. Our work indicates the role of the incorporated Fe atoms and the superficial oxo/hydroxo species of TMPs on their high OER activity. It will be helpful to understand the OER process occurred on phosphide electrocatalysts at atomic scale.

\section{Experimental Section}

Synthesis of $\mathrm{Ni}_{1-x} \mathrm{Fe}_{x}(\mathrm{OH})_{y}$ Nanosheets: A piece of CF was ultrasonically washed with acetone, ethanol, and ultrapure water before use. The precursor solution was prepared as follows. First, $2.25 \mathrm{mmol}$ of $\mathrm{Ni}\left(\mathrm{NO}_{3}\right)_{2} \cdot 6 \mathrm{H}_{2} \mathrm{O}, 0.75 \mathrm{mmol}$ of $\mathrm{Fe}\left(\mathrm{NO}_{3}\right)_{3} \cdot 9 \mathrm{H}_{2} \mathrm{O}, 6 \mathrm{mmol}$ of $\mathrm{NH}_{4} \mathrm{~F}$, and $15 \mathrm{mmol}$ of $\mathrm{CO}\left(\mathrm{NH}_{2}\right)_{2}$ were dissolved in $40 \mathrm{~mL}$ ultrapure water for $30 \mathrm{~min}$ to form a homogeneous solution. Then the uniform solution was transferred into a $50 \mathrm{~mL}$ Teflon-lined stainless steel autoclave. Subsequently, a piece of cleaned CF was immersed into the solution. Finally, the autoclave was heated in at $120^{\circ} \mathrm{C}$ for $6 \mathrm{~h}$. After the reaction, the obtained $\mathrm{Ni}_{1-x} \mathrm{Fe}_{x}(\mathrm{OH})_{y}$ nanosheets/CF was washed with ultrapure water and ethanol for several times and then dried at $60^{\circ} \mathrm{C}$ for $6 \mathrm{~h}$. The $\mathrm{Ni}_{1-x} \mathrm{Fe}_{x}(\mathrm{OH})_{2}$ nanosheets with the various $\mathrm{Ni} / \mathrm{Fe}$ ratios were prepared by adjusting the molar ratios of $\mathrm{Ni}\left(\mathrm{NO}_{3}\right)_{2} \cdot 6 \mathrm{H}_{2} \mathrm{O}$ and $\mathrm{Fe}\left(\mathrm{NO}_{3}\right)_{3} \cdot 9 \mathrm{H}_{2} \mathrm{O}$ with a total quantity of $3 \mathrm{mmol}$.

Synthesis of $\mathrm{O}-\mathrm{Ni}_{x} \mathrm{Fe}_{1-x} \mathrm{P}_{2}$ Nanosheets: This process was carried out in a horizontal quartz tube furnace. The $\mathrm{Ni}_{1-x} \mathrm{Fe}_{x}(\mathrm{OH})_{y}$ on $\mathrm{CF}$ was placed at the downstream side of the furnace and $0.5 \mathrm{~g} \mathrm{P}$ powder (red phosphorus, 98.5\%) was placed at the upstream side of the furnace. At the beginning, the tube furnace was flushed under a $100 \mathrm{sccm}$ Ar flow for three times to thoroughly remove oxygen. Then both of the substrate and powder were quickly heated to $500^{\circ} \mathrm{C}$ within $30 \mathrm{~min}$. And the chemical vapor reaction is kept for 60 min fully convert the $\mathrm{Ni}_{1-x} \mathrm{Fe}_{x}(\mathrm{OH})_{y}$ into O- $\mathrm{Ni}_{x} \mathrm{Fe}_{1_{-x}} \mathrm{P}_{2}$ nanosheets. During the synthesis process, the flow of Ar gas is kept at a rate of $100 \mathrm{sccm}$. The $\mathrm{Ni}_{1-x} \mathrm{Fe}_{x} \mathrm{P}_{2}$ nanosheets with various atomic ratios $(x=0,0.15,0.25,0.35)$ were also synthesized.

Materials Characterization: The morphologies of $\mathrm{Ni}_{1-x} \mathrm{Fe}_{x}(\mathrm{OH})_{y}$ and $\mathrm{O}-\mathrm{Ni}_{x} \mathrm{Fe}_{1-x} \mathrm{P}_{2}$ nanosheets were characterized by Hitach S-4800 SEM under $20 \mathrm{kV}$ and TecnaiF20 TEM at $200 \mathrm{kV}$. The component of those materials were performed by STEM-EDX elemental mapping, EDS, XRD (Philips X'Pert Pro Super) using Cu K $\alpha$ radiation $(\lambda=1.5418 \AA$ ) and XPS (ESCALAB250Xi). The STEM-EDX elemental mapping was characterized by TecnaiF20 and the EDS was carried out on Hitach S-4800.

Electrochemical Measurements: The HER and the OER were performed with an electrochemical station in a typical three-electrode system at room temperature. The HER and OER measurements were carried out in $1 \mathrm{M} \mathrm{KOH}$ solution $\left(\mathrm{N}_{2}\right.$ saturated, $\left.\mathrm{pH} 14.39\right)$ and $1 \mathrm{M} \mathrm{KOH}$ solution $\left(\mathrm{O}_{2}\right.$ saturated), respectively. The $\mathrm{CFs}$ (about $\left.1 \mathrm{~cm}^{2}\right)$ grown various nanosheets were served as WE and a MOE and a graphite rod was worked as $\mathrm{RE}$ and $\mathrm{CE}$, respectively. The overpotentials were calibrated 
to RHE through the equation: $E(\mathrm{RHE})=E(\mathrm{MOE})+0.098+0.059 \mathrm{pH}$. For OER, LSV measurements were conducted from 1.0 to $1.8 \mathrm{~V}$ vs RHE with a scan rate of $2 \mathrm{mV} \mathrm{s}^{-1}$. And for HER, LSV measurements were tested at a scan rate of $2 \mathrm{mV} \mathrm{s}^{-1}$ from +0.1 to $-0.4 \mathrm{~V}$ vs RHE. The overall water splitting was also performed in $1 \mathrm{M} \mathrm{KOH}\left(\mathrm{N}_{2}\right.$ saturated) using a two-electrode configuration. The $\mathrm{O}-\mathrm{Ni}_{x} \mathrm{Fe}_{1-x} \mathrm{P}_{2}$ nanosheets worked as both cathode (HER) and anode (OER). The LSV measurements were performed at a scan rate of $2 \mathrm{mV} \mathrm{s}^{-1}$. All the potentials were calibrated to a RHE. All polarization curves were corrected for $i R$ losses to reflect the intrinsic activity of the catalysts.

DFT Calculations: All spin-polarized calculations were carried out via using the Vienna Ab-initio Simulation Package (VASP) package. ${ }^{[29]}$ The projector augmented wave (PAW) ${ }^{[30]}$ pseudopotential and the RPBE exchange-correlation functional[ ${ }^{[31]}$ were used in the calculation with a $500 \mathrm{eV}$ cutoff energy. More relevant details, references, and data are given in the Supporting Information.

\section{Supporting Information}

Supporting Information is available from the Wiley Online Library or from the author.

\section{Acknowledgements}

K.L. and F.M.W. contributed equally to this work. This work was supported by Ministry of Science and Technology of China (No. 2016YFA0200700), National Natural Science Foundation of China (Nos.61625401, 61474033, 61574050), Strategic Priority Research Program of the Chinese Academy of Sciences (Grant No. XDA09040201), and CAS Key Laboratory of Nanosystem and Hierarchical Fabrication. The authors also gratefully acknowledge the support of Youth Innovation Promotion Association CAS.

\section{Conflict of Interest}

The authors declare no conflict of interest.

\section{Keywords}

density function theory, oxide species, oxygen evolution reaction, phosphides

Received: November 22, 2017 Revised: December 27, 2017 Published online:

[1] a) H. Dau, C. Limberg, T. Reier, M. Risch, S. Roggan, P. Strasser, ChemCatChem 2010, 2, 724; b) M. S. Burke, L. J. Enman, A. S. Batchellor, S. Zou, S. W. Boettcher, Chem. Mater. 2015, 27, 7549.

[2] F. Wang, T. A. Shifa, X. Zhan, Y. Huang, K. Liu, Z. Cheng, C. Jiang, J. He, Nanoscale 2015, 7, 19764.
[3] P. Jiang, Q. Liu, Y. Liang, J. Tian, A. M. Asiri, X. Sun, Angew. Chem., Int. Ed. 2014, 53, 12855.

[4] E. J. Popczun, J. R. McKone, C. G. Read, A. J. Biacchi, A. M. Wiltrout, N. S. Lewis, R. E. Schaak, J. Am. Chem. Soc. 2013, 135, 9267.

[5] Z. Li, X. Dou, Y. Zhao, C. Wu, Inorg. Chem. Front. 2016, 3, 1021.

[6] Z. Huang, Z. Chen, Z. Chen, C. Lv, H. Meng, C. Zhang, ACS Nano 2014, 8, 8121 .

[7] A. Mendoza-Garcia, D. Su, S. Sun, Nanoscale 2016, 8, 3244.

[8] A. Lu, Y. Chen, H. Li, A. Dowd, M. B. Cortie, Q. Xie, H. Guo, Q. Qi, D.-L. Peng, Int. J. Hydrogen Energy 2014, 39, 18919.

[9] E. J. Popczun, C. G. Read, C. W. Roske, N. S. Lewis, R. E. Schaak, Angew. Chem. 2014, 126, 5531.

[10] P. Xiao, M. A. Sk, L. Thia, X. Ge, R. J. Lim, J.-Y. Wang, K. H. Lim, X. Wang, Energy Environ. Sci. 2014, 7, 2624.

[11] P. Lou, Z. Cui, Z. Jia, J. Sun, Y. Tan, X. Guo, ACS Nano 2017, 11, 3705.

[12] a) X.-Y. Yu, Y. Feng, B. Guan, X. W. D. Lou, U. Paik, Energy Environ. Sci. 2016, 9, 1246; b) A. E. Henkes, Y. Vasquez, R. E. Schaak, J. Am. Chem. Soc. 2007, 129, 1896; c) J. F. Callejas, C. G. Read, C. W. Roske, N. S. Lewis, R. E. Schaak, Chem. Mater. 2016, 28, 6017.

[13] L.-A. Stern, L. Feng, F. Song, X. Hu, Energy Environ. Sci. 2015, 8, 2347.

[14] I. Shirotani, E. Takahashi, N. Mukai, K. Nozawa, M. Kinoshita, T. Yagi, K. Suzuki, T. Enoki, S. Hino, Jpn. J. Appl. Phys. 1993, 32, 294.

[15] Y. Li, H. Zhang, M. Jiang, Q. Zhang, P. He, X. Sun, Adv. Funct. Mater. 2017, 27, 1702513.

[16] C. Xiao, B. Zhang, D. Li, Electrochim. Acta 2017, 242, 260.

[17] J. D. Costa, J. L. Lado, E. Carbó-Argibay, E. Paz, J. Gallo, M. F. Cerqueira, C. Rodríguez-Abreu, K. Kovnir, Y. V. Kolen'ko, J. Phys. Chem. C 2016, 120, 16537.

[18] Y. Li, H. Zhang, M. Jiang, Y. Kuang, X. Sun, X. Duan, Nano Res. 2016, 9, 2251.

[19] C. Tang, R. Zhang, W. Lu, L. He, X. Jiang, A. M. Asiri, X. Sun, Adv. Mater. 2017, 29, 1602441.

[20] a) Y. Yang, H. Fei, G. Ruan, J. M. Tour, Adv. Mater. 2015, 27, 3175; b) W. Chen, H. Wang, Y. Li, Y. Liu, J. Sun, S. Lee, J.-S. Lee, Y. Cui, ACS Cent. Sci. 2015. 1, 244.

[21] G. Zhang, G. Wang, Y. Liu, H. Liu, J. Qu, J. Li, J. Am. Chem. Soc. 2016, 138, 14686

[22] S. M. Iveson, J. D. Litster, K. Hapgood, B. J. Ennis, Powder Technol. 2001, 117, 3.

[23] a) S.-J. Park, Y.-S. Jang, J. Colloid Interface Sci. 2003, 263, 170; b) D. Ochs, S. Dieckhoff, B. Cord, Surf. Interface Anal. 2000, 30, 12.

[24] C. Xia, Q. Jiang, C. Zhao, M. N. Hedhili, H. N. Alshareef, Adv. Mater. 2016, 28, 77.

[25] M. W. Kanan, D. G. Nocera, Science 2008, 321, 1072.

[26] X. Xu, F. Song, X. Hu, Nat. Commun. 2016, 7, 12324.

[27] W. Chen, Y. Liu, Y. Li, J. Sun, Y. Qiu, C. Liu, G. Zhou, Y. Cui, Nano Lett. 2016, 16, 7588.

[28] J. Rossmeisl, Z.-W. Qu, H. Zhu, G.-J. Kroes, J. K. Nørskov, J. Electroanal. Chem. 2007, 607, 83.

[29] a) G. Kresse, J. Hafner, Phys. Rev. B 1993, 47, 558; b) G. Kresse, J. Furthmüller, Comput. Mater. Sci. 1996, 6, 15.

[30] a) P. E. Blöchl, Phys. Rev. B 1994, 50, 17953; b) G. Kresse, D. Joubert, Phys. Rev. B 1999, 59, 1758.

[31] B. Hammer, L. B. Hansen, J. K. Nørskov, Phys. Rev. B 1999, 59, 7413. 